\title{
Puccinia jaceae var. solstitialis Teliospore Priming on Yellow Starthistle
}

\author{
A. J. Fisher, B. J. Aegerter, T. R. Gordon, L. Smith, and D. M. Woods
}

First and fourth authors: Exotic and Invasive Weeds Research Unit, U.S. Department of Agriculture-Agricultural Research Service, 800 Buchanan, Albany, CA 94710; second author: University of California Cooperative Extension, 420 S. Wilson Way, Stockton 95205; third author: Department of Plant Pathology, University of California, Davis 95616; and fifth author: California Department of Food and Agriculture, Sacramento 95832.

Accepted for publication 19 September 2008.

\begin{abstract}
Fisher, A. J., Aegerter, B. J., Gordon, T. R., Smith, L., and Woods, D. M. 2009. Puccinia jaceae var. solstitialis teliospore priming on yellow starthistle. Phytopathology 99:67-72.

Following the introduction of Puccinia jaceae var. solstitialis to California for biological control of yellow starthistle (Centaurea solstitialis, Asteraceae), teliospores, pycnia, and multiple urediniospore generations have been observed in the field. Because urediniospores have a relatively short life span in the field, functioning teliospores are expected to be necessary for the permanent establishment of $P$. jaceae var. solstitialis in California. To determine if conditions in California were conducive to this, teliospore emergence and priming were evaluated in the field. A factorial experiment in the laboratory with five incubation times and three incubation temperatures was used to determine teliospore priming requirements. Teliospore production coincided with plant senescence in
\end{abstract}

ABSTRACT
August and September at two sites in 2 years; fewer teliospores were produced in 2006, suggesting inconsistent teliospore production may limit population growth and contribute to local extinctions in some areas. When teliospores were primed in the field, germination was low through the fall and abruptly peaked in January during both years. In the laboratory, teliospore germination increased as incubation time increased from 2 to 6 weeks and temperatures decreased from 12 to $4^{\circ} \mathrm{C}$. A degree-hour model derived from laboratory data accurately predicts when teliospores are primed for germination in the field. Based on the results obtained in this study, it is apparent that teliospore germination can occur over a range of priming conditions. However, lower temperatures and longer incubation periods are superior in breaking teliospore dormancy.

Additional keywords: rust fungi, thermal time.
The rust fungus Puccinia jaceae var. solstitialis ( $P$. jaceae var. solstitialis) was introduced to California for biological control of yellow starthistle (YST, Centaurea solstitialis) in 2003 (6). YST is an invasive winter annual that has infested over 7 million ha in California and continues to spread (16). Since the introduction of $P$. jaceae var. solstitialis, multiple urediniospore generations have been observed on YST, and the pathogen was documented to persist through the host-free months and establish new infections the following winter at one release site (6). In California, YST seeds germinate during the winter wet season beginning in October; rosettes bolt and flower during the summer and plants begin to senesce in the late summer (13).

Prior to the first release, the functionality of teliospores and the importance of a cold priming period prior to germination were established in the laboratory (4). Urediniospores do not survive well on senesced plant material in the field and are thus unlikely to serve as infective propagules on new YST seedlings in winter (7). Previous work suggests that the most likely form of initial inoculum is basidiospores (formed from germinating teliospores), as pycnia have been observed in and around release plots on YST prior to the eruption of uredia (5). To establish the importance of teliospores in the survival of $P$. jaceae var. solstitialis, more information is needed regarding the epidemiology of teliospore emergence and the cold requirement necessary to break dormancy.

Corresponding author: A. J. Fisher; E-mail address: alijfisher@gmail.com

doi:10.1094/PHYTO-99-1-0067

This article is in the public domain and not copyrightable. It may be freely reprinted with customary crediting of the source. The American Phytopathological Society, 2009.
Thermal time, the accumulation of time above a threshold temperature, has been used to model the growth and development of plant pathogens (12). For organisms that require a cold period, a related concept has been used to calculate the accumulation of time below a threshold temperature, or chilling degree-hours (2). Although teliospores of some rust fungi require cold priming to break dormancy $(1,4)$, the accumulation of time below a threshold has not been used in models describing teliospore priming; in fact, few studies provide information on the range of conditions sufficient to break dormancy for teliospores in the Uredinales $(1,4,9,15)$. In this study, dormancy is defined as the period when activity is suspended and germination will not occur, and priming is the process required for resuming activity potentially resulting in spore germination. The focus of prior cold priming studies has been the practical aspects of developing protocols for germinating teliospores in the laboratory. Bruckart and Eskandari (4) developed methods for priming, incubating, and germinating $P$. jaceae var. solstitialis teliospores. At $4^{\circ} \mathrm{C}$, germination increased as the duration of priming increased from one to approximately 7 weeks. Many YST infestations occur in areas where winter temperatures do not drop to $4^{\circ} \mathrm{C}$ for sustained periods, such as coastal and southern California. Consequently, more information is needed regarding the suitable range of priming temperatures and the effect of the length of the priming period on teliospore germination.

To document disease dynamics, teliospore emergence was monitored in the field. Laboratory experiments were used to characterize the range of temperatures sufficient to break dormancy and develop a degree-hour model to predict when teliospores are primed for germination. To test our predictions, we conducted experiments in two distinct habitats, coastal and Central Valley, 
$\mathrm{CA}$, to determine when teliospores are naturally primed for germination under field conditions.

\section{MATERIALS AND METHODS}

Fungal isolate. $P$. jaceae var. solstitialis field isolate FDWSRU 84-71 was collected east of Yarhisar and Hafik (near Sivas), Turkey in 1984. This isolate was evaluated in quarantine at the USDA-ARS, Foreign Disease-Weed Science Research Unit, at Ft. Detrick, MD, and propagation of inoculum took place at the California Department of Food and Agriculture, Sacramento (6).

Teliospore emergence. Teliospore emergence was monitored in 2005 and 2006 at release sites near the cities of Napa (Napa Co.) and Woodland (Yolo Co.), CA. The Napa site is an ungrazed rangeland valley in the coastal hills, $427 \mathrm{~m}$ elevation, dominated by YST, naturalized European annual grasses, native grasses and shrubs, surrounded by oak woodland. The Woodland site is ungrazed rolling hills rangeland, $53 \mathrm{~m}$ elevation, in the Central Valley. It is dominated by naturalized European annual grasses and herbs, surrounded by actively grazed rangeland and agriculture.

Plots were established adjacent to study sites used to develop an optimal release strategy for $P$. jaceae var. solstitialis (6). In January $2005,1-\mathrm{m}^{2}$ plots were inoculated at each site with $200 \mathrm{ml}$ of deionized water containing $50 \mathrm{mg}$ of urediniospores and $0.15 \%$ Tween $20\left(=100 \mathrm{mg}\right.$ of spores $\left./ \mathrm{m}^{2}\right)$ using plastic $250-\mathrm{ml}$ finger pump spray bottles. Plots were reinoculated monthly, if needed, during the first year to maintain and augment infection. In the second year, naturally occurring infections were visible on YST plants at the Woodland site in the area surrounding plots inoculated the previous year. In February 2006, additional plots were inoculated in Woodland to ensure a supply of infected leaves. Leaves were collected from naturally occurring $P$. jaceae var. solstitialis in Woodland from March to early July and from the plots inoculated in February for the late July and August 2006 sampling dates. In Napa, no naturally infected plants were detected in 2006, and a $1-\mathrm{m}^{2}$ plot was inoculated in January, February, and April of that year. At both sites beginning in March of each year, five leaves were collected from infected plants every other week until no infected leaves were available. In the laboratory, spores were washed from each leaf separately in a drop of deionized water on a microscope slide. Urediniospores of this species have one cell and teliospores have two cells. The number of urediniospore and teliospores in a 200 spore sample from each leaf (1,000 spores per site, for each sampling date) was recorded using a compound microscope.

All statistical analyses were carried out using SAS Institute software version 9.1. The Proc Mixed procedure was used to evaluate the effect of site (Napa or Woodland), year (2005 or 2006), sampling date, and the interaction between site and year on teliospore production. Leaf $(\mathrm{n}=5)$ was included as a random factor. The ratio of teliospores to the total number of spores sampled was transformed by $\log (x+0.01)$ to improve normality, as indicated by Shapiro-Wilkes test, and homogeneity of variance as indicated by Levene's test (11).

Priming and incubation of teliospores in the laboratory. YST rosettes were inoculated with $P$. jaceae var. solstitialis urediniospores in a raised outdoor planting bed at the California Department of Food and Agriculture (CDFA) in Sacramento, CA, in the spring of 2004. Plants were watered as needed throughout the spring and summer, and several generations of urediniospores were observed. Teliospores were visible on plants in late August, and stems infected with teliospores were collected in September 2004 and stored at room temperature $\left(22^{\circ} \mathrm{C}\right)$ prior to use.

Methods for germinating teliospores were based on those of Bruckart and Eskandari (4). Infected YST leaves were suspended in $0.1 \%$ water agar containing 3 drops of Tween 20 per $100-\mathrm{ml}$ volume, placed in microcentrifuge tubes, and ground with a glass rod; large plant debris was removed with tweezers. After a 1-min centrifugation, the pellet was resuspended in $0.2 \%$ sodium hypochlorite, allowed to sit for either $30 \mathrm{~s}$ (experiment 1) or $60 \mathrm{~s}$ (experiment 2), and then recentrifuged. The pellet was resuspended and washed twice in sterile water before finally being resuspended in $0.1 \%$ water agar. The concentration of teliospores was determined by counting spores under a hemacytometer, and the concentration was adjusted to approximately 6 spores $/ \mu l$. Three 10- $\mu$ l drops were added to each of six petri dishes $(100 \times$ $15 \mathrm{~mm}$ ) containing $2 \%$ water agar.

Using a factorial experimental design, plates were incubated in the dark at each of three different temperatures: 4,8 , and $12^{\circ} \mathrm{C}$. At each temperature, a set of plates was allowed to incubate for each of the following time periods: 2, 3, 4, 5, and 6 weeks. After this priming period, two YST seeds were added to each plate to stimulate teliospore germination (4). The YST seeds had been surface-sterilized by soaking for $30 \mathrm{~s}$ in $1 \%$ sodium hypochlorite followed by $1 \mathrm{~min}$ in sterile water. The plates were then incubated in the dark at $18^{\circ} \mathrm{C}$ for 7 days. Numbers of germinated teliospores were determined by counting fully formed basidia visible under a compound microscope. The entire experiment was conducted twice.

A regression analysis was conducted using an equation representing the hypothesis that teliospore priming is directly proportional to the accumulation of chilling degree-hours (2). The general equation is $Y=a+b \times(T h-X) \times Z$, where $Y=$ proportion of teliospores germinating, $T h=$ temperature threshold for degreehour accumulation, $X=$ incubation temperature $\left({ }^{\circ} \mathrm{C}\right), Z=$ incubation duration (hours), and $a$ and $b$ are scalars.

Teliospore priming in the field. Forty greenhouse-grown, 5-week-old YST plants were transplanted into a field plot at CDFA in Sacramento in January 2005. Plants were inoculated with $P$. jaceae var. solstitialis urediniospores, covered overnight with a plastic tent enclosure, and then monitored weekly. Several generations of urediniospores were observed. In late summer, teliospores were observed on stems, and on 15 September 2005, stems infected with teliospores were collected. Infected stems were cut into $3-\mathrm{cm}$ sections and three sections were distributed into 88 , white, $100 \%$ polyester fabric bags $(5 \times 8 \mathrm{~cm})$ tied shut with $100 \%$ polyester twine. On the same day plants were harvested, half of the bags were taken to the Western Regional Research Center (WRRC), Albany, CA, in the San Francisco Bay Area, and half were taken to Armstrong Field Station, University of California, Davis, in the Central Valley. At each site, bags were placed in a wire mesh basket on the ground attached to a fence post. From 19 October 2005 to 10 May 2006, four bags were collected every 3 weeks from Davis and Albany and brought to the laboratory at the WRRC to determine if the teliospores were primed for germination.

The following winter, the experiment was repeated using teliospores collected from an introduced population in Sonoma County, CA. P. jaceae var. solstitialis was released at the Sonoma site in the spring of 2004. Teliospores were observed on YST stems near the release site in late summer 2006 and were collected on 4 October 2006. Infected stems were distributed into bags and transported to Albany and Davis using the methods previously described. From 25 October 2006 to 11 April 2007, four bags were collected every 3 weeks from each site and brought to the WRRC to determine if teliospores were primed for germination. In 2006, additional bags were prepared for the Albany site to determine if teliospores remain viable for multiple years.

Methods to determine if teliospores were primed were similar to those suggested by Mendgen (14) with an added surface sterilization step. Teliospores were washed from leaves in $0.1 \%$ water agar containing 3 drops of Tween 20 per 100 -ml volume. Spores were centrifuged for $1 \mathrm{~min}$ in an Eppendorf Centrifuge 54179 (Eppendorf, Cologne, Germany) at 6,000 rpm to break the surface 
tension. To reduce superficial contaminants, spores were treated with an equal volume of $0.1 \%$ sodium hypochlorite for $1 \mathrm{~min}$ followed by centrifugation for $1 \mathrm{~min}$. Spores were then subjected to two cycles of rinsing with sterile water and pelleting by centrifugation for $1 \mathrm{~min}$. The spore suspension was plated onto $1.5 \%$ water agar in three $10-\mu$ drops per petri plate $(100 \times 15 \mathrm{~mm})$. Five YST seedlings were added to the plates, opposite the spore drops, to stimulate spore germination (4). Plates were incubated in environmental chambers (Percival Scientific, Inc., Perry, IA) at $20^{\circ} \mathrm{C}$ in the dark. The percentage of germinated teliospores in each drop was recorded after 7 days by counting fully formed basidia visible under a compound microscope.

We used the Proc Mixed procedure to determine the effect of sampling date and site (Albany or Davis) on teliospore germination. The proportion of teliospores that germinated was the response variable, and site, sampling date, and their interaction were fixed factors. Bag, plate, and drop were included as random factors. To determine the significance of the random factors, we used a $\chi^{2}$ test to compare residual log likelihood values with and without the random factor included in the analysis. The proportion of teliospores that germinated was transformed by the natural $\log (x+0.1)$ to achieve normality.

Evaluating the degree-hour model using field data. To determine if the degree-hour model, based on laboratory data, accurately predicted teliospore priming in the field, the accumulation of degree-hours below a threshold $\left(14.9^{\circ} \mathrm{C}\right.$ based on results of the degree-hour model) was calculated for Albany and Davis from 1 August 2005 to 28 February 2006 and 1 August 2006 to 28 February 2007. Hourly temperature data were obtained from Hobo Pro Series data loggers (Onset, Bourne, MA) at both sites in 2005-2006 and at the Davis site in 2006-2007. Temperature data were obtained from a Weathermaster weather station (MicroGrow Greenhouse Systems, Temecula, CA) at the Albany site in 20062007. For each hour the temperature was $<14.9^{\circ} \mathrm{C}$, the difference between 14.9 and the observed temperature was calculated and a cumulative sum was computed for the 7 month period.

Cumulative hours at selected locations in California. To better assess the impact of temperature requirements on prospects for establishment of YST rust, the accumulation of hours below $14.9^{\circ} \mathrm{C}$ during the winter of 2005 was calculated for various locations in California, focusing on milder coastal and southern locations which are most likely to not have sufficient cooling degreehours to terminate teliospore dormancy (Table 1). Temperature data were obtained from the California Irrigation Management System (CIMIS) network of weather stations maintained by the state of California. Hourly averages of 60 1-min readings were used to calculate the hours below $14.9^{\circ} \mathrm{C}$.

TABLE 1. Accumulated chilling degree hours below $14.9^{\circ} \mathrm{C}$ at selected locations in California from 1 November 2005 to 28 February 2006

\begin{tabular}{lc}
\hline Location & Chilling degree hours $^{\mathrm{a}}$ \\
\hline Oxnard & 6,865 \\
Camarillo & 8,271 \\
Santa Paula & 8,307 \\
Santa Barbara & 8,351 \\
Long Beach & 9,522 \\
Albany & 10,110 \\
Oakland Hills & 11,510 \\
Salinas & 12,840 \\
Escondido & 13,184 \\
Oakville & 14,792 \\
Zamora & 15,153 \\
Delano & 15,535 \\
Davis & 15,872 \\
King City & 15,937 \\
Palmdale & 21,512 \\
\hline
\end{tabular}

a Accumulated degree hours below a threshold of $14.9^{\circ} \mathrm{C}$.

${ }^{b}$ All data are from CIMIS stations with the exception of Albany, in which data are from a Hobo weather logger (Onset Computer Corp.).

\section{RESULTS}

Teliospore emergence. In 2005, teliospores represented a low percentage of the spores recovered from the earliest sampling date in March through early June (Fig. 1). Teliospore production increased in late June at the Woodland site and late July at the Napa site. By mid-August, teliospores had emerged in significant numbers at both sites (Fig. 1). On the final sampling date in Woodland, 100\% of spores collected were teliospores. Analyses indicated the effects of collection site, year, and sampling date were significant $(P<0.0001$ in all cases), reflecting a more substantial increase in teliospore production over time at the Woodland site than in Napa. The site by year interaction was marginally significant $(P<0.0429)$.

In 2006, teliospores were found in fewer samples and in lower percentages within positive samples compared with that in 2005 (Fig. 1). Samples contained teliospores in Woodland in late March and then none were observed until late June. The maximum percentage of teliospores in the spore samples was approximately $40 \%$ in August at the Woodland site. Sampling ended on 25 July at the Napa site and 7 August at the Woodland site because there were no infected leaves available to collect after that time.

Teliospore priming in the lab. Both the temperature and duration of cold period incubation affected priming of teliospores, as indicated by germination rate (Fig. 2). The best degreehour model fitting the results was the following equation: $Y=$ $0.084070 \pm 0.038828[\mathrm{SE}]+0.000047 \pm 0.000008 \times(T h-X) \times Z$, where $Y=$ proportion of teliospores germinating, $X=$ incubation temperature $\left({ }^{\circ} \mathrm{C}\right)$, and $Z=$ incubation duration (hours). The thres-
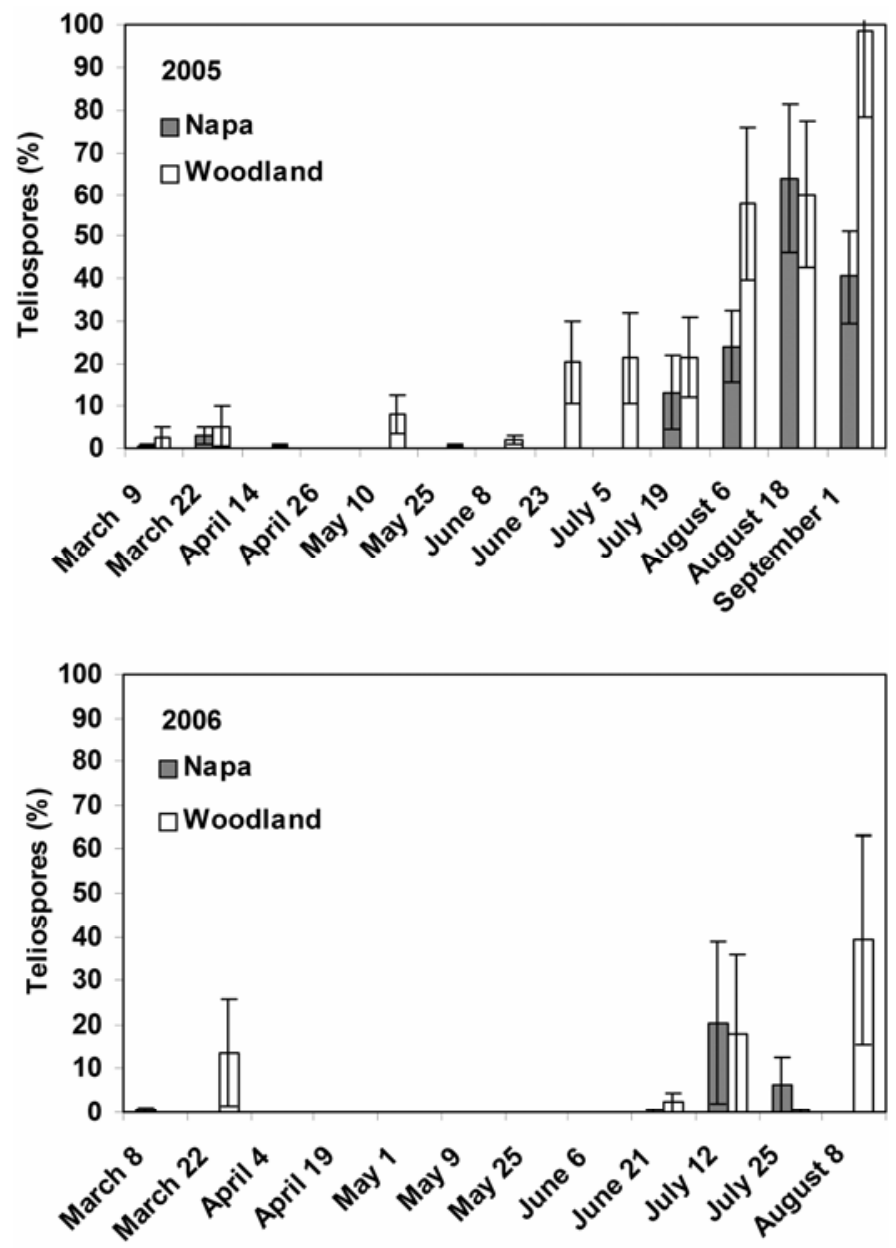

Sampling date

Fig. 1. Percentage of Puccinia jaceae var. solstitialis teliospores in spore samples $(n=200)$ in Woodland and Napa, CA, in 2005 and $2006( \pm$ SE). 
hold temperature was estimated to be $T h=14.93 \pm 2.18^{\circ} \mathrm{C}\left(R^{2}=\right.$ $0.34)$. The degree-hour model fit the data in the observed range; however, the model diverged from the data dramatically beyond 6 weeks. Additional data are needed at longer incubation periods to improve predictions in this range.

Teliospore priming in the field. A small percentage of teliospores germinated at the first sampling date in October in both years (Fig. 3). Low germination percentages continued through the fall and gradually increased until germination peaked in January. Through the spring, germination percentages declined gradually. Site $(P=0.0038)$, year $(P<0.0001)$, and the interaction of the two $(P=0.0103)$ were significant and were therefore analyzed separately. There was a significant difference between sites in $2005(P<0.0001)$ but not $2006(P=0.8935)$. Sampling date differed in both years $(P<0.0001)$ and there was a significant site by sampling date interaction in $2005(P<0.0008)$ and $2006(P<0.0001)$. There was variation between bags in 2005 $\left(\chi^{2}=13.5\right.$, df $\left.=3, P=0.0036\right)$, but no other random factors were significant.

Teliospores that were harvested, bagged, and returned to the WRRC in October 2006 failed to germinate in the fall and winter of 2007. Teliospores were tested for viability in November and December 2007 and January 2008, and no teliospores germinated.

Evaluating the degree-hour model using field data. Our degree-hour model was used to solve for the number of degreehours $(D H)$ when $50 \%$ of teliospores would be primed for germination $(0.5=0.084070+0.000047(D H))$ in the field. According to the model, $50 \%$ teliospore germination should occur after 8,849 degree-hours and this was set as the threshold. In 20052006, 8,849 degree-hours had accumulated in Davis and Albany by 27 December 2005 and 8 January 2006, respectively. In 20062007, 8,849 degree-hours had accumulated in Davis and Albany by 20 December 2006 and 19 January 2007, respectively. The dates predicted by the degree-hour model immediately proceeded or corresponded with observed teliospore germination from spores stored in the field (Fig. 3).

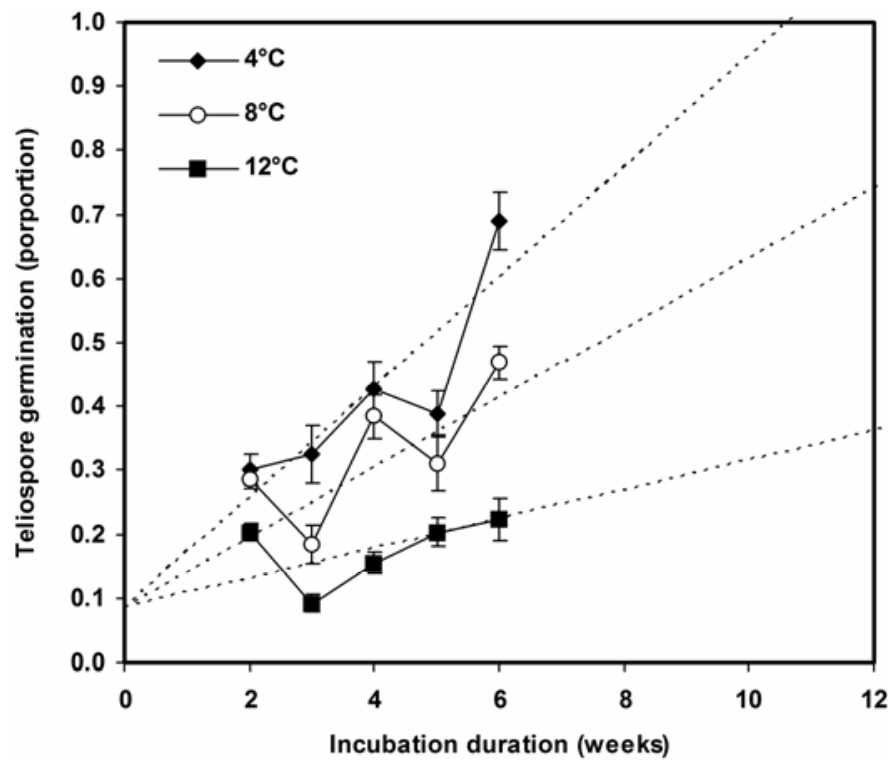

Fig. 2. Proportion of Puccinia jaceae var. solstitialis teliospores germinated in a factorial experiment with three incubation temperatures $\left(4,8\right.$, and $\left.12^{\circ} \mathrm{C}\right)$ and five incubation durations $(2,3,4,5$, and 6 weeks) $( \pm \mathrm{SE})$. Data were fit by a degree-hour model: $Y=0.084070 \pm 0.038828$ [SE] $+0.000047 \pm 0.000008 \times$ $(T h-X) \times Z\left[R^{2}=0.34\right]$, where $Y=$ proportion of teliospores germinating, $X=$ incubation temperature $\left({ }^{\circ} \mathrm{C}\right), Z=$ incubation duration (hours), and the threshold temperature was estimated to be $T h=14.93 \pm 2.18^{\circ} \mathrm{C}$. Dotted lines are predicted germinations for the three incubation temperatures based on the degree-hour model.

\section{DISCUSSION}

As is typical of many rust fungi, $P$. jaceae var. solstitialis teliospore emergence corresponds with high summer temperatures and the beginning of plant senescence (14). In the southern Sacramento Valley, seedling stages begin in November, rosettes emerge in February, flower stages begin in Jun, and senescence occurs from August to October. In this study, the percentage of teliospores in our samples increased from approximately $20 \%$ from late June through early July to $65 \%$ in early August when plants were beginning to senescence. Spreading teliospore production over a longer time span would be an evolutionarily adaptive strategy in years when conditions limit teliospore production during plant senescence. The specific trigger for $P$. jaceae var. solstitialis teliospore production is not known.

For an intentionally introduced pathogen such as $P$. jaceae var. solstitialis, a year with limited teliospore production, as was observed in both study sites in 2006, may limit population growth and ultimately lead to extirpation of local populations. Climatic conditions likely contributed to low teliospore production in 2006. A warm, dry early summer will lead to low urediniospore production. This will result in few pustules to produce teliospores by the time conditions are appropriate for their production. According to National Weather Service stations at the Napa Airport, Napa, CA, and the Sacramento Executive Airport, Sacramento, $\mathrm{CA}$, average daily temperatures between April and September were $1.2^{\circ} \mathrm{C}$ warmer in Napa and $0.5^{\circ} \mathrm{C}$ warmer in Sacramento,
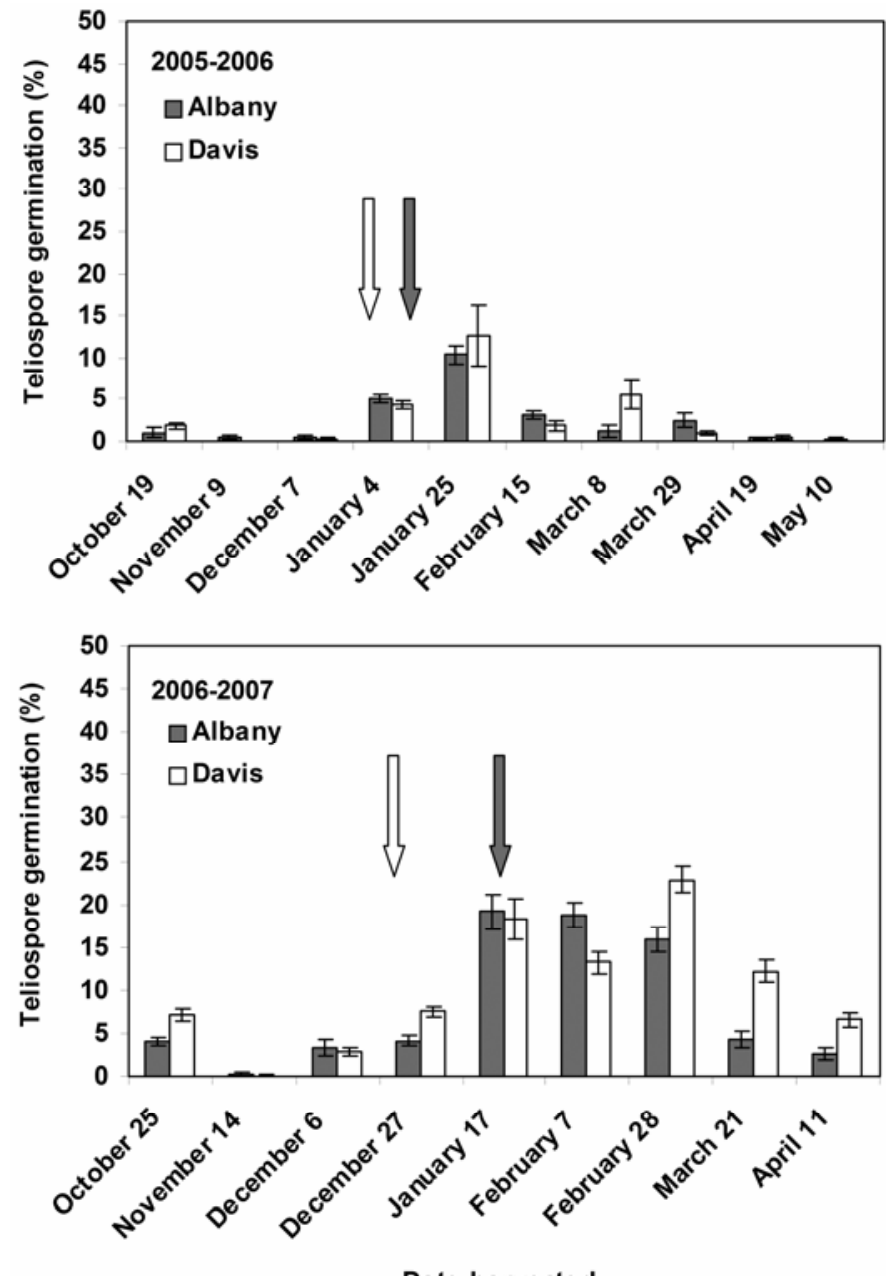

Date harvested

Fig. 3. Puccinia jaceae var. solstitialis teliospore germination (\%) following natural priming in the field in Davis and Albany, CA, during 2005 to 2006 and 2006 to 2007 ( \pm SE). Arrows mark approximate dates at each site when the degree-hour model predicts $50 \%$ teliospore germination. 
in 2006 compared with 2005. In addition, between May and September, daily average precipitation was $9.4 \mathrm{~mm}$ lower in Napa and $8.0 \mathrm{~mm}$ lower in Sacramento in 2006 compared with 2005. Spore production was not quantified in this study. However, it became more difficult to find leaves infected with $P$. jaceae var. solstitialis through the spring and summer of 2006 and the experiment ended in early August, compared to September in 2005 , because there were no infected leaves to collect after that time.

Few studies provide guidelines for the incubation and germination of teliospores in the Uredinales $(1,4,9,15,20)$. Of these, most have characterized the effect of temperature on germination $(9,10,15)$ and not priming requirements specifically. Teliospores of many rusts, including most cereal rusts, must be primed prior to germination $(8,14)$. In addition to cold priming, isolates of $P$. hordei, $P$. recondita, $P$. graminis avenae, and $P$. lagenophorae benefit from presoaking in water at cold temperatures prior to germination. When these species were presoaked in water at $4^{\circ} \mathrm{C}$ for 2 weeks, germination increased compared with teliospores stored dry at $4^{\circ} \mathrm{C}$ (1). Our use of water agar plates was a substitute for soaking in water.

Overall, it is apparent that a range of incubation temperatures will serve to prime $P$. jaceae var. solstitialis teliospores for germination. However, lower temperatures are superior in breaking teliospore dormancy. Our results confirm those of Bruckart and Eskandari (4) that increased incubation from 2 to 6 weeks at $4^{\circ} \mathrm{C}$ results in increased teliospore germination. The results of our incubation study show that higher temperatures $\left(8\right.$ and $\left.12^{\circ} \mathrm{C}\right)$ and shorter incubation durations reduce teliospore germination significantly. However, these results suggest that mild winter temperatures in California should not impose a severe limitation on germination of teliospores.

Models incorporating thermal time, or accumulation of time below a threshold temperature, have historically been underutilized in plant pathology research (12). In its first application to spore priming, our degree-hour model accurately predicted when teliospores were primed for germination in the field. The model predicted that $50 \%$ of teliospore would be primed for germination in late December and early to mid-January in Davis and Albany, respectively. At both sites, in both years, germinations significantly increased in late December and peaked by late January.

All locations for which we evaluated weather data from the winter of 2005-2006 accumulated chilling hours below $14.9^{\circ} \mathrm{C}$, equivalent to or exceeding the 6-week priming period used in our experiments. The Albany site had fewer hours below $14.9^{\circ} \mathrm{C}$ compared with the Davis site and yet our field results indicate that natural priming did occur. Greater limitations may be imposed on the pathogen by environmental requirements for infection by basidiospores and/or urediniospores. The optimal conditions for infection by urediniospores are $20^{\circ} \mathrm{C}$ with 12 to $16 \mathrm{~h}$ of dew (3). These conditions are not likely to be met in all YST populations in California.

Distribution of $P$. jaceae var. solstitialis in its region of origin is similar to that of the native range of YST: southern Europe and western Asia (17). The fungal isolate released in the United States, and used in this study, was collected near Sivas, Turkey. CLIMEX software (CSIRO Publishing, Melbourne, Australia) was used to compare temperatures between Sacramento, CA (neighboring Woodland), and Sivas, Turkey. CLIMEX uses a global meteorological database to compute 20 year averages in climate conditions that can then be used to compare conditions among multiple locations. In general, temperatures in Sivas were lower in both the summer and winter. Particularly in the winter, low temperatures in Sivas are consistently below $0^{\circ} \mathrm{C}$ from November through March. During these same months in Sacramento, frost was rare except for January and in some years February.

The timing of teliospore germination and subsequent spore stages may be critical determinants of the magnitude of the im- pact of $P$. jaceae var. solstitialis on YST. Potential impacts were assessed in quarantine prior to the first release. Repeated inoculations of 4-week-old YST plants, over a 3 to 4 week period, resulted in a $40 \%$ reduction of root weights and a $50 \%$ reduction of shoot weights $(3,18)$. The negative effect on root biomass was even greater when plants were drought stressed (19). These studies suggest that $P$. jaceae var. solstitialis has the potential to negatively impact very young YST plants. To expect similar results in the field, YST would have to become infected at the young rosette stage. According to Maddox (13), seedlings begin to emerge in October though seeds can continue to germinate through the spring depending on precipitation patterns. Results of this study suggest that if teliospores germinate in January, it is possible for urediniospores to emerge and infect plants during the seedling stage. However, many seedlings will be a few months old by this time. More work is needed to assess the impacts of $P$. jaceae var. solstitialis on YST plants at multiple phenological stages.

For biological control agents with complex life cycles, such as rusts, many factors may limit success in an introduced range. Previous work documenting consecutive urediniospore generations, the presence of pycnia and the reemergence of uredia following yellow star thistle's dormant phase when there are no plants to infect, suggests that $P$. jaceae var. solstitialis undergoes its full life cycle in California. Observed teliospore production and priming under natural conditions is further evidence that $P$. jaceae var. solstitialis has the potential to establish permanently in North America. Inconsistent teliospore production, however, may limit population growth and contribute to local extinctions in some areas. To improve the likelihood of establishing local populations, future work is needed to understand the processes that stimulate teliospore production and to identify climate and landscape characteristics of successful release sites.

\section{ACKNOWLEDGMENTS}

We thank V. Popescu, L. Kong, and M. Plemons for technical support and B. Bruckart for comments on this manuscript. This study was financially supported by the USDA Research Associate Program and a grant from the UC-IPM Exotic/Invasive Pests and Disease Research Program.

\section{LITERATURE CITED}

1. Anikster, Y. 1986. Teliospore germination in some rust fungi. Phytopathology 76:1026-1030.

2. Arnold, C. Y. 1959. The determination and significance of the base temperature in a linear heat unit system. Proc. Am. Soc. Hortic. Sci. 74:430-445.

3. Bennett, A. R., Bruckart, W. L., and Shishkoff, N. 1991. Effects of dew, plant age, and leaf position on the susceptibility of yellow starthistle to Puccinia jaceae. Plant Dis. 75:499-501.

4. Bruckart, W. L., and Eskandari, F. 2002. Factors affecting germination of Puccinia jaceae var. solstitialis teliospores from yellow starthistle. Phytopathology 92:355-360.

5. Fisher, A. J., Bruckart, W. L., McMahon, M. B., Luster, D. G., and Smith, L. 2006. First Report of Puccinia jaceae var. solstitialis pycnia on yellow starthistle in the United States. Plant Dis. 90:1362.

6. Fisher, A. J., Woods, D. M., Smith, L., and Bruckart, W. L. 2007. Developing an optimal release strategy for the rust fungus Puccinia jaceae var. solstitialis for biological control of Centaurea solstitialis (yellow starthistle). Biol. Control 42:161-171.

7. Fisher, A. J., Woods, D. M., Smith, L., and Bruckart, W. L. 2008. Latent period and viability of Puccinia jaceae var. solstitialis urediniospores; Implications for biological control of yellow starthistle. Biol. Control 45:146-153.

8. Johnson, T. 1941. Longevity of teliospores of Puccinia graminis under laboratory conditions. Phytopathology 31:197-198.

9. Klisiewicz, J. M. 1972. Effect of host plant materials and temperature on germination of teliospores of Puccinia carthami. Phytopathology 62:436438.

10. Klisiewicz, J. M. 1977. Effect of flooding and temperature on incidence and severity of safflower seedling rust and viability of Puccinia carthami teliospores. Phytopathology 67:787-790. 
11. Levene, H. 1960. Robust tests for the equality of variances. Pages 278261 in: Contributions to Probability and Statistics: Essays in Honor of Harold Hotelling. Stanford University Press, California.

12. Lovell, D. J., Powers, S. J., Welham, S. J., and Parker, S. R. 2004. A perspective on the measurement of time in plant disease epidemiology. Plant Pathol. 53:705-712.

13. Maddox, D. M. 1981. Introduction, phenology, and density of yellow starthistle in coastal, intercoastal, and central valley situations in California. U.S. Agric. Res. Serv. West. Reg. Rep. ARS-W20.

14. Mendgen, K. 1983. Development and physiology of teliospores. Pages 375-398 in: The Cereal Rusts, vol. 1. W. R. Bushnell and A. P. Roelfs, eds. Academic Press, New York.

15. Morin, L., Brown, J. F., and Auld, B. A. 1992. Effects of environmental factors on teliospore germination, basidiospore formation, and infection of Xanthium occidentale by Puccinia xanthii. Phytopathology 82:14431447.

16. Pitcairn, M. J., Schoenig, S., Yacoub, R., and Gendron, D. 2006. Yellow starthistle continues to spread in California. Calif. Agric. 60:83-90.

17. Savile, D. B. O. 1970. Some Eurasian Puccinia species attacking Cardueae. Can. J. Bot. 48:1553-1566.

18. Shishkoff, N., and Bruckart, W. L. 1993. Evaluation of infection of target and nontarget hosts by isolates of the potential biocontrol agent Puccinia jaceae that infect Centaurea spp. Phytopathology 83:894-898.

19. Shishkoff, N., and Bruckart, W. L. 1996. Water stress and damage caused by Puccinia jaceae on two Centaurea species. Biol. Control 6:57-63.

20. Turner, S. K., Kwiatkowski, A., Fay, P. K., and Sands, D. C. 1986. Factors affecting germination of teliospores of Puccinia obtegens. Plant Dis. 70:390-391. 